\title{
How Engineering Design Learning May be Improved: Thoughts, Practices, and Recommendations
}

\section{Dr. Waddah Akili, Iowa State University}

Waddah Akili has been in the academic arena for over 37 years. He has held academic positions at Drexel University, Philadelphia, Penna (66-69), at King Fahd University of Petroleum \& Minerals, Dhahran, Saudi Arabia (69-87), and at the University of Qatar, Doha, Qatar (87-00). Professor Akili's major field is geotechnical engineering and materials. His research work \& experience include: characterization of arid and semi arid soils, piled foundations, pavement design \& materials, and concrete durability. His interests also include: contemporary issues of engineering education in general, and those of the Middle East and the Arab Gulf States in particular. 


\title{
How Engineering Design Learning May be Improved: Thoughts, Practices, and Recommendations
}

\begin{abstract}
Design is considered by most to be the central activity of engineering. Also, it is known that engineering programs should graduate engineers who can design effectively to meet social and environmental needs. Though the role and perception of design across a wide range of educational institutions have improved markedly in recent years; however, both, design faculty and design practitioners argue that further improvements are necessary. One of the defining characteristics of design is that there is rarely a single correct answer to an engineering problem but, rather, an optimal or acceptable solution leading to a final design, presented as the best possible balance between technical as well as non-technical constraints. These non-technical constraints, typically involve: economics, politics, social and environmental issues, ethics, etc. And, while professional practitioners generally accept this understanding of design, students, by enlarge, tend to interpret the engineering design process as an unambiguous and clearly defined process supported by rigidly applied principles and processes of "the scientific method." Students' vision and mis-concepts of design do require proper alignment with prevailing conditions on the ground. Undoubtedly, the start of any design course should be preceded by exposure to design thinking and related processes. The paper reviews the role of design in engineering programs, and outlines the current research on how design thinking processes could be taught and learned. It explores also the currently most-favored pedagogical model for teaching design, namely: Project-Based Learning (PBL). The paper identifies several contexts for PBL, along with some available data on it success. Finally, the paper raises some of the questions that should be answered to identify the most effective pedagogical practices of improving design learning.
\end{abstract}

\section{Introduction}

Design is widely considered to be the most distinguishing activity of engineering. It has also long been understood that engineering institutions should graduate engineers who could design effectively to meet societal needs. Historically, engineering curricula have been based largely on an "engineering science" model, referred to as the "Grinter Model", in which engineering is taught only after a solid basis in science and mathematics. The resulting engineering graduates were perceived by industry and academia, at the time, as being "ill-prepared" for the practice. Despite steps taken to remedy the situation, through greater industry-academia collaboration, Both design faculty and design practitioners argue that further improvements are necessary. Design faculty across a range of educational institutions still feel that the leaders of engineering schools (deans, department heads, tenured faculty) are unable or unwilling to recognize the intellectual complexities and resources needed to support good design education.

Fortunately, more and more educators are becoming aware of the issues of design, and steps are being taken world wide, to address the concerns of industry at large. One approach has been to form "symbiotic" partnership between industry and academia through senior capstone projects. 
The capstone course has evolved over the years from "made up" projects devised by faculty to industry-sponsored projects where companies provide "real" problems, along with expertise and financial support. In fact, design courses, in general, have emerged as a means for students to be exposed to some flavor of what engineers actually do; and also, could learn the basic elements of the design process by being involved in real design projects. There have even been formal proposals for curricular goals and assessment measures for design-based curricula. This argument is driven by a widespread notion that the intellectual content of design is consistently underestimated $^{(1)}$.

This paper reviews research on design thinking as it relates to how designers think, learn and make decisions, which is an important reason why design is not easy to teach. Design thinking is, in general terms, complex processes of inquiry and learning that designers perform in a systems context, making decisions as they move forward, often working collaboratively in a social setting, and eventually arriving at an optimum solution. The paper, also, focuses on the most favored pedagogical model for teaching design, namely: project-based learning (PBL), as an effective way for students to learn design by experiencing design as active participants. The paper closes by making recommendations for ways to enhance design learning.

\section{On Engineering Design Thinking and Learning}

What does "design" mean in an engineering context? What are the qualifications of a designer? Can design be taught? And if so, who can teach it? These questions will be addressed in the paragraphs that follow.

Relevant Definitions, Thoughts and Processes: Engineering design as stated by Dym et al. in 2005 is: "a systematic, intelligent process in which designers generate, evaluate, and specify concepts for devices, systems or processes whose form and function achieve clients' objectives or users' needs while satisfying a specified set of constraints"(1). This definition presents design as a thoughtful process that depends on systematic, intelligent generation of design concepts and the specifications that make it possible to realize these concepts ${ }^{(2)}$. Sheppard's characterization of what engineers as designers do: "They scope, generate, evaluate, and realize ideas" (3). In the context of engineering design, creativity is important, but it is not design! Design problems do reflect the hard fact that the designer has many constraints that may positively or negatively affect the outcome of the design, i.e., the designer has a client to satisfy and for whose benefit the item/artifact and/or project is being developed.

There are many approaches to characterizing design thinking and design processes. These characterizations, often associated with good designers, would include the following ${ }^{(2)}$ :

- view design as an inquiry and/or iterative loop of divergent-convergent thinking,

- focus on the "big picture" in all stages by including systems thinking and systems design,

- handle uncertainties that are likely to arise,

- arrive at decisions,

- think and act as a member of a team,

- think and communicate using known languages of design,

- Be familiar with relevant background and technical knowledge that lead to successful design. 
The starting point of any design project, irrespective of the object or nature of the project, is the problem definition phase characterized by asking relevant questions and attempting to find plausible/realistic answers. No sooner has a client or professor defined a series of objectives for a design project than the designer- whether in a consulting office or in a classroom- want to find out what the customer really wants. Questions such as: what is an economic project? How do you define the best design? What is a safe design? What are the factor(s) that will affect the design the most? Phrasing it differently, knowledge resides in the questions that can be asked and the answers that can be provided ${ }^{(2,3)}$.A sequence of inquiry characterized by a hierarchy: certain questions need to be asked and answered before other questions can be asked. There is a set procedure which constitutes the inquiry process in an epistemological context. Taxonomies of such a procedure or inquiry process have been extended to computational models ${ }^{(4)}$, to the intricacy between asking and learning ${ }^{(5)}$, and would also apply to the questions students ask during a class and/or tutoring session ${ }^{(6)}$.

There are two classes of questions within a design context; the first is the category of questions that do have a specific answer, or a specific set of answers. Such questions are characteristic of convergent thinking, where the questions attempt to converge on and reveal "facts". As such, answers to converging-type questions are expected to be truthful and verifiable. The second category of questions is diametrically opposite to the first, and is characteristic of divergent thinking, where multiple alternative known answers exit, regardless of being true or false. The key distinction between the two types is that convergent questions operate in the knowledge domain; whereas divergent questions operate in the concept domain ${ }^{(1)}$.This has strong implications for teaching conceptual design thinking, since concepts need not be truthful or have true value, whereas knowledge does. Design thinking therefore is seen as a series of transformations from the concept domain to the knowledge domain. Such questioning and thinking is the "backbone" of any design process, and the major tool by which designers add to the pool of engineering knowledge ${ }^{(7)}$. The significance of the transformations between the concept and knowledge domains is further supported by the finding that the combined incidence of deep reasoning questions and generative design has been shown to correlate positively with performance, in arriving at design solutions ${ }^{(8)}$.Therefore, any properly produced design is preceded by effective inquiry that includes both a convergent component (lower level and deep thinking questions) and a divergent component (generative design questions intended to create the concepts upon which the design is based).

The forgoing discussion raises questions relevant to teaching design in all engineering disciplines. Clearly, the divergent inquiry in design thinking is neither recognized nor included in most engineering curricula. I think the time is right to introduce the iterative divergentconvergent process(s) in order to develop better pedagogical approaches to engineering design.

Focusing on Design-Related Education: Recently, designers, throughout the world, have helped develop an increasingly complex "built" environment that includes some major largescale engineering projects. Simultaneously, designers have been pushing the envelope at relatively fast rate making products, systems and engineering projects increasingly more complicated as they strive to improve reliability and increase service-life by increasing number of components and their interdependencies. Further, designers have to expand the design boundaries to include environmental factors, social factors, and public safety issues in their 
designed systems and projects. The author believes that engineering designers are in need of skills and experience to help them cope with the complexity and facilitate the arrival at optimum design. Invariably, this type of: knowledge, skills, and related experience need to find its way to the classroom through curricula updating, proper counseling, mentoring, and insuring a conducive classroom environment.

There are four aspects of design education believed to be of relevance to acquiring and/or enabling young designers, and students in particular, to embark on the mission. The four are highlighted in the subsections to follow.

1) Thinking about a system's approach: A good designer is some one who can anticipate and deal with intended and unintended consequences resulting from interactions among the multiple factors of the system. Exposure to system analysis and system dynamics - preferably through rigorous courses - would assist the designer in sorting variables, prioritizing, and managing the design process. Unfortunately, these skills are not common, do require prerequisites, and regarded by most as difficult to learn. Many different teaching methods have been proposed to improve people's abilities to grasp and retain knowledge under this category. Recognizing that there are difficulties in proper delivery of systems analysis and systems dynamics to engineering students; the fact remains that these tools are extremely useful for someone who plans to become a designer. Therefore, ways have to be found to enhance the understanding of systems' thinking, and at the same time, to develop educational experiences that could efficiently improve learning outcomes.

2) Looking at risk management and uncertainty: Engineering design is carried out relying on incomplete data, imperfect models, often with unclear objectives, and other potential problems and constraints. The effects of such uncertainties on the design of a project may have serious consequences unless proper safeguards have been undertaken based on probabilistic and statistical approaches to design and factors affecting design. Some have argued that current undergraduate curricula greatly underemphasize the theory and application of probability and statistics in engineering ${ }^{(9)}$. Research has revealed that people are generally prone to serious errors in probabilistic and statistical thinking, including neglect of prior probabilities, insensitivity to sample size, and misconceptions of regression ${ }^{(10)}$.The formal course work in probability and statistics falls terribly short of exposing engineering students to various encountered errors, e.g., systematic underestimation of uncertainty. Engineering educators are concerned, and some have been working to alleviate the difficulties by stressing conceptual understanding, emphasizing active teaching methods, and using more graphics \& simulations. ${ }^{(11)}$ There is a long way to go with regard to uncertainty and the way it ought to be handled in the classroom. Suggested improvements and changes, by some researchers, have included the following: ${ }^{(12)}$

- offer probability and statistics courses early on in the program,

- include "uncertainty" and its implications in engineering analysis courses,

- consider offering technical electives, in this domain, and let "uncertainty" be a central theme,

- Make use of modern computational tools to support probabilistic thinking. 
Such curriculum changes may fall short of meeting set goals without adequate research aimed at continued improvements in probabilistic and statistical thinking for engineering in general and the design component in particular.

3) Estimation: A main challenge of a project design is the number of variables and their interactions during the design process. Often, the system stretches beyond designers' capability to grasp all of the details simultaneously ${ }^{(1)}$. One strategy for coping with the many variables is to bring the system back within the limits of human mental capacity by focusing selectively on a limited number of factors, preferably the most significant ones. Designers are usually good at estimation. They are able to size up parameters, sort them out in terms of their relative importance, and neglect the ones that have less impact on the project. Today's graduates are not good at estimation ${ }^{(1)}$.The poor performance by the new graduates appears to be related to a weak conceptual understanding of basic engineering science, limited ability to form appropriate analogies, weakness in visual perception, short-term memory, and insufficient interaction with their physical surroundings ${ }^{(4,5)}$. Additionally, current engineering education emphasizes sophisticated methods for precise calculation and thus may underemphasize approximation skills ${ }^{(13)}$.Attempts to rectify the situation would require research and development and eventually instigating potential changes in curricula and teaching methods.

4) Physical modeling and experimentation: Unfortunately, the advent of the computer and its impact on teaching engineering has made it easy to produce computer-based models at the expense of physical models. This fact is behind a general trend of teaching applied engineering subjects with minimal students' involvement with physical set-ups including laboratory experiments. Carrying out laboratory experiments and generating experimental data, visiting a project site, and using pencil and paper to produce a schematic, are gradually fading away. These traditional tools were instrumental in developing an engineering common sense. It is argued here that generating data from physical models is potentially a great learning tool, particularly when the model is built by the students. Building a model, testing a model, generating physical data from the model, and analyzing said data, help students alternate between inductive and conductive processes, thus broadening their design vision and their understanding of the experimental approach to engineering design. There is potentially a real need to research the ways to teach engineering students how to make proper use of physical models and experiments.

The four aspects (discussed above): thinking about a systems approach, looking at risk management/uncertainty, estimation, and physical modeling and experimentation - are intended to pin point some shortcomings in design-related education that need to be addressed, using a principled approach to dealing with these issues.

\section{Development and Growth of Design Thinking in a Team Environment}

All aspects of design is being recognized and taught today in most institutions as a team process with socio-technological dimensions. ${ }^{(13)}$ One practical reason is that ABET general engineering criteria target the social aspects of engineering education at several levels. In addition to criterion 3(c), "an ability to design a system, component, or process to meet desired needs," criterion 3(d) addresses the need to function on multidisciplinary teams, criterion 3(f) social and ethical responsibilities, criterion $3(\mathrm{~g})$ communication skills, and criterion $3(\mathrm{~h})$ addresses global and social impact. Constructivist theories of learning, irrespective of the subject matter, recognize 
that learning is a social activity, and design-based courses, including project-based courses, are regarded by most as opportunities to improve students' ability to work in teams, as well as their communication skills. As a result, universities now incorporate many of these aspects in their design classes, ranging from first-year design courses to capstone design. In fact, many of the early researchers have emphasized that the design process requires the designer to continually raise questions, and exchange views with others over the advantages and disadvantages of alternative solutions. ${ }^{(14)}$ Also, design has been defined by some as "a social process" in which teams define and negotiate decisions and each team member posses an "ingrained" set of technical capabilities that could act as a filter during design team interactions and, consequently, the end result is an intersection - not a simple summation of participants inputs. This view of design has received the attention of many researchers, and was used by some to develop relevant pedagogies, to promote multidisciplinary discourse and constraint negotiations. ${ }^{(15)}$

Several researchers investigated the role that gender plays in design education and in forming design teams. ${ }^{(16)}$ The results have shown that background and technical knowledge are far more important than gender and/or ethnicity. There is also a wide body of research in design practice and design learning on the use of psychometric measurement of personality type, such as MBTI, to analyze and predict the behavior and likelihood of success of teams in general. ${ }^{(17,18)}$ Such techniques have been successfully applied to forming design teams in engineering classes, particularly the use of MBTI that has shown that better outcomes are achieved with teams consisting of members with complimentary roles, a plurality of viewpoints, and a neutral team leader. ${ }^{(19)}$ Much effort has been devoted to furthering the understanding of individual influences on team behavior. More insight may be gained by exploring the relationship between personality and learning style preferences ${ }^{(20)}$. Lent et $\mathrm{al}^{(21)}$ have described the effect of collective efficacy, a team's beliefs about its capabilities to work together, on the cohesion and satisfaction of the team. They found that negative feelings of collective efficacy may limit outcome expectations, requiring remedial steps to promote effective teamwork. Clearly, more research appears needed on applying set measures to analyze team behavior and to form teams, and on furthering the understanding of the impact of individual diversity factors on team performance.

\section{Project-Based Learning}

Project-based learning (PBL) begins with an assignment, to one or more students, to carry out specific tasks that would eventually lead to the arrival of a final product- a design, a model, a device and/or a computer simulation. The end result is normally a written and/or an oral report highlighting the main steps undertaken to produce the product and the outcome. (Note: the acronym PBL is also used to denote problem-based learning. But it is used here to refer to project-based learning). At the initial stage, there are two approaches: either the instructor chooses the project, which helps maintain a focus on course and curriculum objectives. The second is to allow students the autonomy to choose their own project: its general objective, its formulation and strategies and their approach to it, which, most likely, tend to increase students' motivation and self reliance. Which is best? The answer is to be decided taking into consideration students' prior experience, their skills, and students' abilities to use available resources.

De Graaf and Kolmos ${ }^{(22)}$ define three types of projects that differ in the degree of student autonomy: 
- Task project: Student teams work on projects that have been defined by the instructor, using primarily instructor-prescribed methods. This type of project is part of traditional instruction in most curricula, and results in minimal student motivation and skill development. It falls under traditional instruction as per most engineering curricula.

- Discipline project: the instructor selects and defines the subject area of the projects and specifies in general terms the methods to be used (involves common methods usually deployed in the subject area and usually known to students), but the students identify the specific project and select the method/approach they decide to follow to complete the project.

- Problem project: In this type of project students have complete autonomy to choose their project and their approach to it from beginning to end.

The common difficulty faced by students in a PBL environment is the ability to transfer methods and skills acquired in one project to another project in a different setting or discipline. Instructors should include such transference in their course objectives and should guide students to see connections between their current project and what they have learned previously, and gradually withdrawing this support as the students gain knowledge and become more capable of seeing the connections by themselves. The instructors should also prepare students to fill in gaps in content knowledge when the need arises, taking into account the fact that such gaps are likely to arise in PBL than in conventional lecture-based instruction ${ }^{(22)}$.In essence, PBL addresses one of the key issues in the cognitive sciences, transfer, which can be defined as the ability to extend what has been learned in one context to other new contexts ${ }^{(23)}$.This is an important component of engineering competency development. While the design studio has long been a centerpiece of design thinking and pedagogy outside engineering, it took the medical community to lead engineers back to thinking formally about PBL and related pedagogies. Project-based learning at the individual course level is known in engineering education, having been used almost universally in capstone design and in first-year engineering courses and in courses that engage students in consulting projects. A few European schools, including the Universities of Aallborg and Roskilde in Denmark, and others in Europe and Australia, have made PBL the focus of most of their engineering courses ${ }^{(24)}$.

The use of PBL in medical schools demonstrated that the first-year students were significantly better diagnosticians, i.e., practitioners, than those taught by lecturing ${ }^{(25)}$.Today, the professions are converging; engineering, medicine, law, and business are moving toward similar project-and problem-based pedagogic frameworks. The evidence is clear- that PBL encourages and supports collaborative work, and that it improves retention and enhances design thinking. However, there remains the need to extend the results already obtained and to demonstrate as well PBL's values in increasingly authentic design scenarios that typically include participation across disciplines, as well as across geographical boundaries ${ }^{(1)}$.

Introducing PBL in the First Year: The first year design-oriented courses are similar to many capstone design courses, but differ markedly in their tendency to focus more heavily on conceptual design methods and less on discipline-specific artifacts.(e.g., cars in mechanical eng., chips in electrical eng.), primarily because there are now many accessible sources of information, including textbooks, and also, because most first year students can do reasonable conceptual design without the detailed technical knowledge they acquire only later in their programs. In fact, there is a strong belief that first year design-oriented courses: 
- Enhance student interest in engineering as well increase students' retention in engineering programs;

- Motivate learning in upper division engineering science courses; and,

- Enhance performance in design courses in general and in capstone design courses in particular.

While there are different views of the proper metric for assessing retention, there seem to be enough data to support the thesis that a design course or a course that contains design elementsincluding projects, teams and written and oral communication- can produce very positive changes in engineering student retention rate ${ }^{(25)}$. In terms of other measures of potential benefits of design courses, much data is available from various institutions. Purdue's EPICS program reports that students regarded team work, communication, and time management and/or organization as "the three most valuable things learned" from the EPICS course. (26) There is strong evidence that supports the statement noted above ${ }^{(27)}$ including assessment data on the impact of PBL \&design courses on student' benefits, general outcome, \& future career ${ }^{(28)}$. Mills and Treagust ${ }^{(29)}$ reviewed published evaluations of PBL programs in engineering and concluded that students who participate in PBL early on, are more motivated, demonstrate better communication and teamwork skills, and have better understanding of professional practice and how to apply their learning to real problems; however, some may have less complete mastery of engineering fundamentals , and some may have "second thoughts" about the time and effort required by projects and the interpersonal conflicts they experienced in team work, particularly with teammates who fail to devote the time and effort required to get the job done properly. In addition, if the project work is done entirely in groups, some of the students may be less equipped to work independently.

Intertwining PBL with Problem-Based( The Hybrid Approach):Curricula with high concentration of Project Based Learning intertwined with Problem Based Learning were assessed at the University of Louvain ${ }^{(30)}$. The assessment measures included pretests and posttests of students' basic knowledge, understanding of concepts and the ability to apply them. Also, students' self-efficacy, satisfaction with the curriculum, attitudes towards team work, instructors teaching practices, and the impact of the "hybrid" curriculum( project/problembased) on the instructional environment. The results of the Louvain assessment are extremely supportive of the "hybrid" (project/problem-based) curriculum. Students in the "hybrid" curriculum expressed their satisfaction with the new curriculum, because: they received a lot of support from the instructors, saw more connections between theory and practice became more willing to use autonomous learning strategies, and were less reliant on rote memorization relative to students in the traditional curriculum ${ }^{(30)}$. The positive outcomes for the "hybrid" curriculumtaught students is attributed to two main factors: factor one, is the great support received from their instructors; factor two, students' perceptions that they should work harder than students taught traditionally. Teachers in this study saw a positive impact of the "hybrid" curriculum on student competencies in team work, transfer of knowledge, and learning; the quality of student teacher interactions and teacher-teacher interactions; and teachers' pleasure in teaching and their willingness to change their teaching practices to make it compatible with the new system they have adopted ${ }^{(24,30)}$.The last two outcomes were particularly strong among teachers who perceived their administration to be supportive of teaching, in general, and valuing teaching 
improvement in particular. This outcome has important implications for the critical role of college administrators in attempts to reform education.

\section{Getting Started with Design Courses, Including: Project-Based Learning}

Once instructors are persuaded that design and design -related pedagogies are worth attempting, they face the question of which method to use, and when is the appropriate time embark on the selected method(s). The answer, like the answer to any real question, begins with "it depends"; it depends specifically on the instructor's learning objectives, his or her prior experience with learning-centered teaching methods, instructor's teaching skills and his/her willingness to acquire new skills when the need arises, and the availability of local expertise and support for each of the selected methods. Before teaching a topic or series of lessons using design-related pedagogy, the instructor should focus on learning objectives that define what the students should be able to do (search, calculate, derive, analyze, design, model, critique,...) after the course and/or instruction has been concluded. The learning objectives should guide the choice of focal points, learning activities, potential changes, and assessment methods. Once learning objectives have been defined, a suitable instructional method(s) may be identified. When the decision regarding the adoption of a method, or methods, is made, the instructor should refer to relevant tects, articles, and Web-based resources on the chosen method(s) and take full advantage of experienced colleagues and teaching center consultants who can offer advice on implementing selected method(s) and dealing with problems that may arise with its use.

There is a clear need to expand the number of faculty members interested in and capable of teaching design including project-based design courses. The most important recommendation is that engineers in academe, both faculty members and administrators, make enhanced design pedagogy one of their highest priorities in future resource allocation decisions. In addition, there are ways of approaching design education that can offer systematic payoffs and help in setting up a framework for continuous quality enhancement. ${ }^{(1,2,13)}$ These include the following:

- Encourage experienced design faculty to help mange the contextualization of engineering design theory and practice. This would not only bring invaluable experience into the classrooms, but would also alleviate the shortage of faculty who want to teach design.

- Adopt the idea that engineering design courses, and related courses, should be taught across geographically dispersed, culturally diverse, international networks. ${ }^{(1)}$

- Challenge all engineering faculty to incorporate the tools of design thinking into relevant parts of the engineering curriculum.

- Alert the administration to the cost of lost human design potential resulting from the lack of investment in design pedagogy.

- Provide forums where design practitioners, design teachers, design researchers, and experts from industry to come together to discuss and collaborate on all aspects of design teaching.

Finally, design education represents both serious challenges and great opportunities for faculty, college and stakeholders. On the other hand, it is clear that incorporating the elements discussed above will raise the cost of education (smaller sections, involvement of experts, etc.), but, on a macro, or global scale, these costs are small compared to the cost of lost human talent in the engineering pipeline. Design is what engineers do, and if proper steps are taken to improve design education, both students and the instructor should soon start seeing positive outcomes. 


\section{Concluding Remarks}

On the whole, the intended move towards encouraging instructors to adopt project-based learning (PBL) seems farfetched and difficult to accomplish, especially in the initial stage. This is because time is needed for those undertaking the task to be trained to implement and gain the experience necessary to move the process forward. Time is also needed for other stakeholders to be convinced and provide the support needed to prescribe the change. Most importantly, those promoting the change must be able to show evidence that PBL is effective for engineering education. It is highly recommended that an "Active Learning Taskforce" be formed of experienced faculty, to initiate, infuse, and oversee the progress made. Their determination, patience, and resilience are required to successfully promote college-wide implementation of PBL. Nevertheless, with clear intention, goals and plans of action, coupled with support from the highest level of the University's key personnel, the Taskforce and other core groups, should be able to move the process forward. Success would almost be guaranteed, when a well-coordinated College -wide implementation of PBL is underway in other departments and colleges of the University.

\section{References}

1. Dym, C.L., Agogino, A.M., Eris, O., Frey, D.D., and Leifer, L.J., (2005), "Engineering Design Thinking, Teaching, and Learning," Journal of Engineering Education, Vol.94, no.1, pp.103-120.

2. Dym, C. L., and Little, L. (2003), Engineering Design: A Project-Based Introduction, $2^{\text {nd }}$ ed. John Wiley, New York, N.Y.

3. Sheppard, S. D., (2003), “A Description of Engineering: An Essential Backdrop for Interpreting Engineering Education," Proc. (CD), Mudd Design Workshop IV, Harvey Mudd College, Claremont, Cal.

4. Lehnert, G. W., (1978), The Process of Question Answering, Lawrence Erlbaum Associates, Hillsdale, N.J.

5. Graesser, A., K. Lang, Horgan, D., (1988) “A Taxonomy for Question Generation,” Questioning Exchange, Vol2, no.1, pp.3-15.

6. Graesser, A., and Person, N., (1994), "Question Asking during Tutoring," American Educational Research Journal, Vol. 31, no.1, pp.104-137.

7. Vinventi, W. G., (1990), What Engineers Know and How They Know It: Analytical Studies from Aeronautical History, Johns Hopkins Univ. Press, Baltimore, Md.

8. Eris, o., (2004), Effective Inquiry for Innovative Engineering Design, Kluwer Academic Publishers, Boston, Mass.

9. Hazelrigg, G.A., (1994), "Rethinking the Curriculum: Is Today’s Engineering Education Irrelevant, Incomplete, and Incorrect?" Prism, ASEE, Wash. D.C.

10. Kahnemann, D., Slovic, D.P., and Tversky, A.,(1982), Judgment Under Uncertainty: Heuristics and Biases, Cambridge Univ. Press, Cambridge, England.

11. Ramos, J., and Yokomoto, C., (1999) "Making Probabilistic Methods Real, Relevant, and Interesting Using MATLAB," Proceedings, 1999 Frontiers in Education Conf., Institute of Electrical and Electronic Engineers.

12. Wood, W. H., (2004), "Decision-Based Design: A Vehicle for Curriculum Integration," International Journal of Engineering Education, Vol.20.no.3, pp. 433-439.

13. Dym, C.L., Wesner, J.W., and Winner, L., (2003), "Social Dimensions of Engineering Design: Observations from Mudd Design Workshop III,"Journal of Engineering Education, Vol.92, No.1, pp.105-107.

14. Rittel, H.W.J., and Webber, M.M.,(1973), "Dilemmas in a General Theory of Planning,"Policiy Sciences, Vol.4, ,pp.155-169

15. Bucciarelli, L. L., (1994), Designing Engineers, Cambridge, Mass., MIT Press. 
16. NSF'S Program for Gender Equity in Science, Technology, Engineering and Mathematics: A Brief Retrospective 1993-2001, Wash. D.C., National Science Foundation, 2002.

17. Barrick, M. R., Stewart, G. L., Neubert, M. J., and Mount, M.K., (1998), "Relating Member Ability and Personality to Work Team Processes and Team Effectiveness," Journal of Applied Psychology, Vol. 83, No. 3, pp.377-391.

18. Reilly, R.R., Lynn, G.S., and Aronson, Z.L.,(2002), "The Role of personality in New Product Development Team Performance," Journal of Engineering \& Technology Management, Vol.19, No.1, pp.39-58.

19. Wilde, D., (2000), "Design Team Formation Using Jungian Typology,"Proc, National Collegiate Inventors and Innovators Alliance.

20. Jensen, G. H.,(1987), "Learning Styles," in Provost, J. A., and Anchors, S., eds., Application of the Myers Briggs Type Indicator in Higher Education, Palo Alto, Cal.: Consulting Psychologist Press, pp.181-206

21. Lent, R. W., Schmidt, L., Schmidt, J., and Pertmer, G.,(2002), "Exploration of Collective Efficacy Beliefs in Student Project Teams: Implications for Student and Team Outcomes," Proc.,, ASEE Conf.\& Exhibition.

22. de Graaf, E., and Kolmos, A.,(2003), "Characteristics of Problem- Based Learning," International Journal of Eng. Education, Vol.19, No.5, pp.657-662.

23. Bransford, J. D., Brown, A. L., and Cocking, R. R.,(1999), "How People Learn: Brain, Mind, Experience and School," Wash. .D.C.: National Academy Press.

24. Wessel, D., "Building a Better Engineer," Wall Street Journal, December 20, 2003, p.B1.

25. Saddler, P.M., Coyle, H., and Schwartz, M., (2000), "Engineering Competitions in the Middle School Classroom: Key Elements in Developing Effective Design Challenges," Journal of the Learning Sciences, Vol.9, No.3, pp.313-314.

26. Oakes, W. C., Jamieson, L. H., and Coyle, E. j.,(2001), "EPICS: Meeting EC 2000 Through Service Learning," Proc., ASEE Conference and Exhibition, Session 3461.

27. Bright, A., and Dym, C. L., (2004), "General Engineering at Harvey Mudd: 1957-2003," Proc., ASEE Conf. and Exhibition, Session 1471.

28. Adams, R. S., Turns, J., and Atman, C. J., (2003), "Educating Effective Engineering Designers: The Role of Reflective Practice," Design Studies, Vol. 24, No. 3, pp.275-294.

29. Mills, J. E., and Treagust, D. F., (2004), "Engineering Education- Is Problem - Based or Project - Based Learning the Answer?" Australasian Journal of Engineering Education, www.aaee.com. Au/journal/mills_treagust03.pdf.

30. Galand, B., and Freney, M.,(2005), " The Louvian Curriculum and Evaluation of its Effectiveness," http:// vidio.aau.dk/lectutres/120/120 cwtng.html 